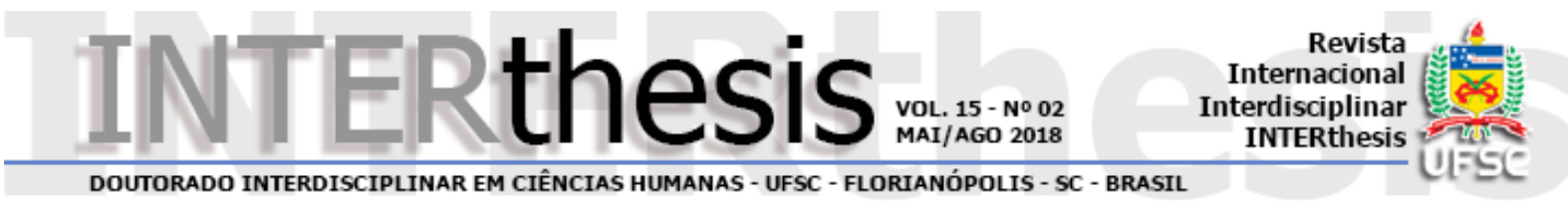

\title{
CIDADE, UNIVERSIDADE E PERCEPÇÕES DOCENTES NO CONTEXTO DA EXPANSÃO INTERIORIZADA DO ENSINO SUPERIOR PÚBLICO NO ESTADO DO CEARÁ
}

\author{
Carlos Henrique Lopes Pinheiro ${ }^{1}$
}

\section{Resumo:}

Este artigo tem como objetivo discutir a relação cidade/universidade a partir do processo de expansão e interiorização das instituições públicas de ensino superior no estado do Ceará. O desenvolvimento deste trabalho apoiou-se na pesquisa de base qualitativa, privilegiando abordagens narrativas sobre as trajetórias docentes, investigando o modo como os mesmos percebem e mantêm relações com o local de trabalho. Foram realizadas entrevistas com diretores de centros e com 49 docentes (27 do gênero masculino e 22 do gênero feminino) em todos os campi onde existem cursos presenciais de Instituições de Ensino Superior Públicas - IESP (estadual e/ou federal) no Ceará. A partir do material produzido foi possível constatar que existem inúmeras dificuldades de reconhecimento e pertencimento do/a docente com seu local de trabalho, que a análise da interiorização do ensino superior deve ser realizada, também, considerando aspectos subjetivos dos sujeitos que as constituem, que as dificuldades estruturais das cidades e o modo como o/a docente percebe, senti e se identifica com estas cidades pode resvalar sobre as condições e organização do trabalho por ele/a desenvolvido.

Palavras-Chaves: Ensino Superior. Expansão e Interiorização. Cidade e Universidade. Trabalho Docente.

\section{INTRODUÇÃO}

Fruto de inúmeras e profundas transformações pelas quais tem passado a educação superior brasileira nos últimos anos, o fluxo ou a circulação de professores universitários pelo interior do estado do Ceará tem se tornado um evento cada vez mais constante e significativo. O processo de interiorização proporcionou, indubitavelmente, uma crescente mobilidade socioespacial dos docentes neste Estado. No entanto, a "expansão territorializada" expôs uma relação, muitas vezes conflituosa, do/a docente com o a cidade onde trabalha e, de certo modo, uma

\footnotetext{
${ }^{1}$ Doutor em Sociologia pela Universidade Federal do Ceará. Pós-Doutorado em Conhecimento e Inclusão social em Educação pela Universidade Federal de Minas Gerais. Professor na área das Ciências Humanas dos Cursos de Bacharelado e do Mestrado Interdisciplinar em Humanidades do Instituto de Humanidades e Letras da Universidade da Integração Internacional da Lusofonia AfroBrasileira em Redenção, CE, Brasil. E-mail: carlos.henrique@unilab.edu.br
} 
"negação" em permanecer nestes municípios um tempo maior do que o efetivamente "necessário" para o exercício de suas atividades laborais. Não raro, independentemente do tempo de permanência semanal em seus locais de trabalho, os/as docentes expressam sentimentos como "eu trabalho aqui, mas moro em Fortaleza" ou "Aqui é meu lugar de trabalho, meu lugar de vivência é outro".

Mas, afinal, "por que ficar, principalmente, aqui e não em outro lugar"? O questionamento de Schaller (2008, p.67), elaborado para conceber o lugar enquanto espaço dialético, constitutivo do eu, aprendente ${ }^{2}$ em suas palavras, que remete à relação da pessoa com ela própria e com os outros, se mostra bastante pertinente às nossas análises. Para além da existência corpórea (material) o lugar, conforme Santos (2012), se define aqui por sua existência relacional, pela sua funcionalidade e por onde ele é vivido e percebido empiricamente, no qual através e a partir dele é possível tomar consciência do mundo. Nesta perspectiva, a inversão da pergunta se mostra igualmente relevante para pensarmos sobre decisões e percepções dos docentes interlocutores: Por que não ficar, principalmente, aqui e sim em outro lugar?

Este trabalho traz elementos e algumas reflexões sobre a problemática da relação cidade/universidade dispostas pela apreensão dos/as docentes interlocutores/as da pesquisa. Pela pertinência que o tema ganhou nas abordagens de campo por ocasião da tese de doutorado "Percepções e Trajetórias Docentes: mobilidade no contexto da interiorização e expansão do ensino superior público no estado do Ceará, desenvolvida no programa de Pós-Graduação em Sociologia da Universidade Federal do Ceará (2013), optamos por dá-lo um tratamento especial, específico, voltado para a reflexão tanto do papel que as universidades desempenham nas cidades que se instalam (ao menos o que se espera que elas desempenhem) como da percepção dos agentes que nelas atuam, no caso, seus professores efetivos já aprovados no estágio probatório, ou seja, com no mínimo três anos de exercício profissional no serviço público.

\footnotetext{
${ }^{2}$ Ao longo de todo o texto referendado, o autor faz inúmeras definições do que denomina de "lugar aprendente". Aqui apresentamos uma delas que, no nosso entendimento, sistematiza a ideia proposta: "Um lugar, através da atualização das redes de atores que o atravessam é aprendente porque permite deixar marcas do conjunto das relações, das ligações, das associações entre os atores. Cada elo dessas redes pode se tornar um evento, uma bifurcação, traduzindo a inteligência coletiva dos atores e os processos de historização aos quais se submetem as práticas, as experiências e as ações transformadoras desses atores. Nesse sentido, todo lugar é aprendente. Assim os lugares se constituem e aprendem ao mesmo tempo em que ensinam e constituem os atores que vivem neles".
} 
Partimos, então, de considerações sobre a análise do espaço urbano no que se refere, especialmente, às condições de moradia, saneamento, saúde, lazer, educação escolar, dentre outras, sempre que pertinentes e articuladas aos impactos produzidos e/ou esperados pela consolidação ou instalação de IES em determinadas cidades. Em um segundo momento, buscamos diferenciar as percepções de professores e professoras, pois o olhar sobre a cidade, a relação desta com a universidade e o sentido dado à mobilidade são assimilados de modos distintos. Tais percepções se apresentaram quase sempre de forma passional, tendenciosa, recheados de tabus, cobranças sociais e preconceitos diversos.

Desde já se faz importante considerar que as análises e relatos aqui expostos são parciais, ou seja, nem esgotam o tema, nem tampouco, se fazem totalizantes a todos os demais professores que compõem o efetivo docente dessas universidades.

\title{
2 A PRODUÇÃO E ORGANIZAÇÃO DO ESPAÇO URBANO COM E A PARTIR DA INSTALAÇÃO DAS IES: DISCUTINDO A RELAÇÃO CIDADE/UNIVERSIDADE.
}

A relação entre a cidade e a universidade é, em princípio, inquestionável. Inquestionável porque, ao se entender a cidade como lócus das relações sociais, da pluralidade das manifestações culturais e políticas, e das múltiplas interações e conflitos dos mais variados temas e comportamentos que nelas se expressam, a universidade surge e se mostra como o lugar na/da cidade onde a reflexão dessas dimensões se faz contínua e tem como propósito congregar as diferenças, estimular o debate político, propiciar o desenvolvimento econômico, social e tecnológico, tanto no plano local como regional e, às vezes, global.

\begin{abstract}
Assume-se neste texto a existência de uma interdependência forte e complexa entre a cidade e a universidade. Trata-se de ver essa relação como imantada por algo que, talvez, se possa chamar, como Goethe e Max Weber o fariam, de "afinidade eletiva", no sentido que não se está, seja diante de uma correlação simples, seja de uma justaposição mecânica. Cidade e universidade são complexos interligados por determinações e fecundações recíprocas. Reivindica-se aqui que tanto a natureza, quanto o destino daquelas instituições, a cidade e a universidade, são algumas das melhores promessas da modernidade, promessas de liberdade e emancipação efetiva da humanidade. (Paula 2006, p.35).
\end{abstract}

A universidade por sua vez, designa à cidade, uma concepção de modernidade (no sentido de progresso), de desenvolvimento e de inserção no mundo contemporâneo. Nesta perspectiva, a universidade tende a atribuir à cidade um 
caráter emancipatório, e é muitas vezes vista e entendida como formadora e aglutinadora de lideranças diversas, capaz de iniciar e apaziguar conflitos, de legitimar ou desqualificar discursos políticos. É, ainda, um lugar citadino onde esperanças são depositadas ou, ao contrário, é também um espaço negado, tida como inalcançável, elitista, arrogante ou inoperante por parte da sociedade. Por isso, independente da natureza dos olhares, dos apoios ou críticas, os espaços acadêmicos não são, jamais, ignorados. Desse modo, Henrique (2012) entende que

A compreensão do papel das universidades como agentes de (re)estruturação urbana e das cidades torna-se importante, tanto em razão do volume de recursos financeiros movimentados quanto pela modificação de dinâmicas intraurbanas (moradia, circulação, usos, etc.), e do cotidiano dos moradores.

As faculdades e/ou universidades têm sido implantadas como estratégia de desenvolvimento e modernização local e regional, em especial nas cidades pequenas (entendidas aqui conforme sugere Corrêa (2011), desde aspectos populacionais, de centralidade regional e funcionalidade na rede urbana que a compreende (principalmente educacional, após a instalação de IES) ou mesmo a partir da confluência do rural com o urbano) e médias, aquelas que desempenham destacado papel político e econômico para uma dada região, bem como para a própria unidade federativa (Estado) e que, segundo Andrade (2015)

se apresenta como um espaço atrativo para o deslocamento de moradores de sua região de influência, por motivações diversas, como as práticas laborais, socioculturais, educacionais e de consumo.

Elas têm atribuído às cidades em que se localizam, prestígio, destaque político, funções regionais, além de certa dependência de alguns municípios de sua abrangência. Logo, vê-se que, em linhas gerais, as IES são capazes de movimentar, modelar e remodelar o espaço urbano e as dinâmicas sociais, uma vez que possuem potencial para promover impactos diretos e indiretos como geração de empregos; construção de edifícios impulsionando a construção civil; atração de profissionais qualificados; abertura e/ou melhoria de novos comércios (hotéis, pousadas, restaurantes, etc.); novos e melhores serviços (de saúde, educação, transporte, lazer, etc.).

Claval (apud Henrique, 2012) tece uma série de ideias destacando a importância das universidades para as cidades:

a) As universidades foram importantes para o desenvolvimento das atividades culturais: professores escrevem nos jornais locais. Estudantes e professores são grande parte dos frequentadores de operas e teatros; b) As 
universidades tem um papel central no processo de industrialização em função da Tecnologia. Na Alemanha, Suíça e Estados Unidos a conexão entre as universidades $e$ as indústrias foi priorizada e promoveu o desenvolvimento industrial em muitas cidades universitárias; c) As universidades tem um importante papel na vida política, através de seus professores e estudantes. Professores, mesmo alguns estudantes, contribuem para a criação e difusão de ideologias modernas e são apoiadores de movimentos liberais, radicais, socialistas, etc. A concentração de jovens em uma mesma cidade dinamiza a vida política e 'facilitou' a ocorrência de manifestações e mesmo revoltas urbanas.

As ideias de Paul Claval, assim como as demais concepções acima, são formatos ideais das relações possíveis entre cidades e universidades. As cidades que pesquisamos foram de muitos modos impactadas por suas faculdades e/ou universidades ${ }^{3}$. Todavia, em algumas delas existem uma série de "promessas não cumpridas" e de situações não consolidadas de parte a parte como vida acadêmica intensa, poucas atividades de pesquisa e extensão, melhoria dos serviços, crescimento do comércio atrelado à universidade, investimentos na produção e organização do espaço urbano, dentre outras.

\begin{abstract}
Você passou quanto tempo aqui? Nesse tempo que você ficou você encontrou pelo menos uma pousada decente? Dormiu aonde, comeu o que? Ficou satisfeito? Você só passou dois dias aqui e tão cedo não volta mais. $\mathrm{E}$ nós que vivenciamos este ambiente semanalmente? Eu já estou aqui há mais de dez anos e sabe o que mudou? Nada. Desde quando entrei escuto dizer que a cidade vai melhorar, que a universidade conseguirá implantar um novo padrão cultural... Social e culturalmente não posso dizer que está a mesma coisa, embora a mudança tenha sido muito pequena, mas espacialmente, do ponto de vista urbano, se mudou algo, foi para pior. A cidade é um atraso. É deprimente. Posso até estar exigindo demais, mas só quero me sentir bem, só quero que parte das promessas que escutei desde quando vim pra cá, sejam cumpridas, sejam efetivadas. (...) Eu mesma, já não acredito mais. (sic.Professora Carolina da UECE em Tauá).
\end{abstract}

Ao observar as cidades que percorremos, de fato encontramos e vivenciamos ${ }^{4}$ naquelas onde existem os campi da Universidade estadual do Ceará - UECE, estruturas urbanas "pouco atraentes", especialmente no que se refere às condições de hospedagem (em boa parte das cidades pesquisadas existiam apenas uma opção

\footnotetext{
${ }^{3} \mathrm{O}$ trabalho de campo foi realizado nas seguintes universidades e cidades e ocorreu entre os anos de 2010 e 2012. 01. Universidade Estadual do Ceará (UECE) - Cidades: Limoeiro do Norte, Quixadá, Iguatu, Itapipoca, Tauá, Crateús. 02. Universidade Regional do Cariri (URCA) - Cidades: Crato, Juazeiro do Norte, Iguatu, Campos Sales, Missão Velha. 03. Universidade Estadual do Vale do Acaraú (UVA) - cidade: Sobral 04. Universidade Federal do Ceará (UFC) - Cidades: Quixadá, Sobral, Juazeiro do Norte e Barbalha.

${ }_{4} \mathrm{O}$ termo aqui utilizado possui duplo significado e perspectiva: a) busca refletir uma estratégia metodológica de inspiração etnográfica capaz de representar a imersão exigida pelo trabalho de campo; b) é fiel ao desenvolvimento das atividades docentes realizadas sempre em cidades interioranas por este pesquisador antes, no decorrer e após o doutorado (atualmente, inclusive), tanto o Ceará quanto em Minas Gerais.
} 
de instalação como pensão ou pousada); transporte e mobilidade urbana deficitário (o serviço de mototáxi quase sempre era o único meio de "transporte público"); além da precariedade quanto a opções e condições dos estabelecimentos de/para alimentação, dentre outras condições mais gerais como acúmulo de lixo, esgotamentos a "céu aberto", ruas (vias) não pavimentadas (destacadamente, em vários casos, onde a IES se situa), iluminação pública deficiente, etc. Vale destacar que foram realizadas visitas recorrentes a cada uma dessas cidades e universidades e, em cada trabalho de campo, o tempo de permanência variava entre 3 e 5 dias seguidos. É certo, porém, que estas universidades trouxeram e trazem, quanto aos resultados gerados, impactos positivos. Todavia, quando vários professores afirmam: "a universidade está na cidade, mas não pertence a ela”, compreendemos, conforme sugerido por eles, que esse "distanciamento" ocorre a partir da pouca (ou insuficiente) oferta de serviços e comércios que organizam e produzem os espaços citadinos.

É importante considerar que o estudo do espaço urbano enseja uma abordagem interdisciplinar, uma vez que pode envolver a relação entre as dimensões materiais e simbólicas; objetiva, na perspectiva de sua racionalização disciplinar de produção e reprodução, bem como subjetiva, referindo-se às formas de sociabilidade, resistências, pertencimento que refletem a pluralidade das práticas sociais e, por conseguinte, a necessidade de se compreender as múltiplas dimensões dos fenômenos e das questões urbanas pela via da complexidade, da articulação de saberes eruditos ou não, enfim, pela construção de conhecimentos a partir da aproximação, do diálogo e da articulação de propostas e perspectivas diversas. $O$ aumento do contingente populacional, ao requerer crescente infraestrutura e volume de serviços, promove uma configuração ocupacional bastante complexa, com múltiplas e conflitantes demandas a serem atendidas. No bojo destes serviços, a instalação de um campus universitário enseja, tanto para a população local, quanto para a comunidade acadêmica em geral e para o poder público que, não raro, capitaliza politicamente tais investimentos, novas perspectivas sociais, culturais, econômicas e políticas, designando, muitas vezes, uma sensação de progresso, de desenvolvimento e de modernidade.

Desta forma, acreditamos que a atração e instalação de um equipamento universitário é capaz de proporcionar transformações importantes na organização e na dinâmica do espaço urbano tanto na construção e valorização imobiliária, novas formas de comércio e impulsão de algumas atividades do setor terciário, quanto na 
ressignificação de espaços públicos, manifestações culturais e políticas, mobilidade e/ou fixação de novos habitantes ou transeuntes. Chartier (1990, p. 177) oferece elementos para a compreensão dessas modificações afirmando que “... não há prática ou estrutura que não seja produzida pelas representações, contraditórias e em confronto, pelas quais os indivíduos e os grupos dão sentido ao mundo que é o deles".

A busca pela compreensão das práticas socioespaciais, permeadoras do cotidiano citadino, implica em compreendê-la como sugere Oliveira (1995), em um quadro de vulnerabilidade composto por dimensões sociais, políticas e econômicas, espaciais e culturais. Segundo Lima (2003),

\begin{abstract}
A realidade, eivada de práticas sociais significativas, revela, então, uma cidade que também se molda por uma população que sobrevive pela busca permanente de um lugar no mundo, sob a qual constrói sentidos múltiplos de explicação de sua condição social. (p.65/66).
\end{abstract}

Com base nas transformações e dinâmicas urbanas elencadas logo acima, consideramos que a expansão e interiorização do ensino superior público é fruto da necessidade de incorporação de novas áreas ao processo produtivo que pressupõe, dentre outros aspectos, espaço físico e condições gerais para a produção e reprodução da vida acadêmica.

Neste elo, Santos (1997) observa o espaço urbano enquanto sistemas de objetos e de ações que se materializam e criam forma na cidade, caracterizando-a como um espaço de variados usos, como os de livre circulação de pessoas, mercadorias e capitais, onde se desenvolvem as relações socioespaciais, denominadas pelo autor de binômio fixos e fluxos, no qual adverte que,

\footnotetext{
Esses objetos e essas ações são reunidos numa lógica que é, ao mesmo tempo, a lógica da história passada (sua datação, sua realidade material, sua causação original) e a lógica da atualidade (seu funcionamento e sua significação presentes). (p.63).
}

Diante deste contexto, buscamos discutir até que ponto as características citadinas e a própria localização geográfica dessas cidades são determinantes - ou pelo menos influenciam - para as dinâmicas socioespaciais, e como os professores definem e redefinem os seus espaços de vivência, suas estratégias de sociabilidade e ainda como articulam cotidianamente suas relações pessoais (familiares) e profissionais.

Deste modo, a análise do fenômeno urbano alcança a esfera da vida cotidiana no âmbito do trabalho, do lazer e da vida privada. De Certeau, ao tratar das relações cotidianas afirma que a cidade possui identidade e memória onde através do 
imaginário o espaço urbano "renova-se mais do que se inova, reabilita-se mais do que se constrói, protege-se mais do que se cria" (1994, p.191).

\begin{abstract}
A reflexão sobre a cidade é, fundamentalmente, uma reflexão sobre a prática sócio-espacial que diz respeito ao modo pelo qual se realiza a vida na cidade, enquanto formas e momentos de apropriação. Assim, o espaço urbano apresenta um sentido profundo, pois se revela enquanto condição, meio e produto da ação humana. (Carlos, 2004, p.07).
\end{abstract}

Não há aqui uma tentativa de generalização das das características urbanas das diversas cidades pesquisadas. Ao contrário, é evidente que os processos de desenvolvimento urbano, da oferta de serviços e de toda a dinâmica urbana envolvida nestas cidades são únicos, peculiares, dotados de situações sociais, culturais, políticas e econômicas bem específicas.

No entanto, o que nos chamou especial atenção foi o fato de, mesmo considerando os aspectos populacionais e a disposição dos serviços de lazer, educação, cultura, comércio, dentre outros, os discursos proferidos pelos/as docentes apresentam basicamente as mesmas narrativas, sentimentos e reflexões independente da dimensão e complexidade urbana de cada cidade investigada. Logo, o que se vislumbra são olhares sobre as cidades articulados com as atividades desenvolvidas - docência - em situações próprias de desenvolvimento das mesmas e uma postura comparativa com seus lugares de origem e, principalmente, com grandes centros urbanos, destacadamente a cidade de Fortaleza, principal referência citada pelos entrevistados.

\title{
3 VOZES DO LUGAR: A ORGANIZAÇÃO DAS ATIVIDADES DOCENTES EM FACE DO LUGAR DE TRABALHO.
}

Enfim, como destacado, o lugar importa! Partimos da premissa que ele muitas vezes é ignorado no início, ao ponto do professor desconhecer seu lugar de destino (da atividade profissional), porém, logo se torna tema e preocupação central no que condiz às relações familiares, às estratégias de sociabilidade, às condições e organização do trabalho, ou seja, a toda uma dinâmica paralela de vida que, aparentemente, é posta em "segundo plano" quando comparada à estabilidade profissional, à realização de se tornar professor universitário e de todas as aspirações e possibilidades que a função sugere.

Sinceramente, quando fiz o concurso há oito anos, meu único sentimento era de medo. Não sei se tinha mais medo de passar e ter que conviver, pelo 
menos durante um tempo da semana, em um lugar que nem conhecia, só sabia que era distante e pequeno ou se o meu medo era de não passar e ter que ficar perambulando nas IES privadas ou sendo professor substituto lá na UECE de Fortaleza pelo resto da vida. Passei e vim pra cá, mas até hoje não sei se foi a decisão mais acertada. Ganhei estabilidade, perdi sociabilidade. (...) Aqui é nosso lugar de trabalho, não há condições de se viver definitivamente em Crateús. Não para quem é de cidade grande como eu e a grande maioria daqui. A sorte é que fico somente dois dias aqui, vou e volto toda semana. Embora mais acostumado, na hora do percurso a minha sensação é a mesma: o aperto no peito ainda é o mesmo. (Professor Cícero do curso de Pedagogia da UECE -FAEC, em Crateús).

O professor em destaque, efetivo desde 2002, afirma saber, ainda, que a cidade "não tem culpa", para ele: "essa é a sua dinâmica, são suas características". Complementa dizendo que "não é a cidade que tem que se adequar a nós professores, somos nós que temos que nos adequar à cidade, mas não é fácil... Te garanto, já tentamos, mas definitivamente, não dá". "Os lugares são, portanto, tomados nas redes de interesses e de experiências que neles manifestam os sujeitos. Os indivíduos transformam o seu entorno e essas transformações afetam o que eles são e o que fazem. (Schaller 2008, p.69)".

Assim, "o lugar remete à relação da pessoa com ela própria e com os outros: o lugar é homólogo e constitutivo do eu, como o é de outrem" (Op. cit. P.68). Mas do que com ele próprio e com os outros, o indivíduo mantém um olhar e uma relação com o território em si. Com este, ele desenvolve uma identificação que lhe é própria, particular. Desenvolve sentimentos de pertencimento, de reconhecimento, de "gratidão ou de repulsa". Ao observarmos as características dos lugares pesquisados, optamos por estabelecer dois grupos de análises considerando que a cidade de Sobral e a região do Cariri, diferente das demais, são polos regionais metropolitanos com processos de desenvolvimento distintos (bem mais avançados em termos de estrutura de comércio, serviços e indústrias) e que exercem política e economicamente papel de destaque no estado do Ceará. As demais cidades, embora política e regionalmente importantes, são consideradas cidades de pequeno porte de menor complexidade de forte confluência com o ambiente e modo de vida rural.

a. Das cidades que possuem campus da UECE: Limoeiro do Norte, Crateús, Tauá, Itapipoca, Iguatu e Quixadá. Sendo que Iguatu possui unidade da URCA e Quixadá campus da UFC; 
b. Da cidade de Sobral e das cidades de Juazeiro do Norte e do Crato na Região do Cariri, nestas além dos campi da UFC ${ }^{5}$, existe ainda a UVA em Sobral e a URCA no Cariri.

Ao tratarmos de cada um desses campi ou universidades, podemos perceber que no primeiro grupo, mesmo considerando suas particularidades, que as estruturas urbanas são semelhantes, e que os olhares sobre as cidades, também. De modo geral, existe um percentual muito baixo de professores que decidem permanecer nestas cidades. Os que não permanecem emitem uma percepção comum, geralmente relacionada à precariedade das condições de trabalho e desenvolvimento de pesquisas, dificuldades enfrentadas pelo distanciamento familiar, além de não se satisfazerem com os serviços de saúde, educação para os filhos, lazer, transporte e atividades culturais.

Fatores econômicos e sociais como educação básica, serviços elementares de saúde e emprego seguro são importantes não apenas por si mesmos, como o papel que podem desempenhar ao dar às a oportunidade de enfrentar o mundo com coragem e liberdade. Essas considerações requerem uma base informacional mais ampla, concentrada particularmente na capacidade de as pessoas escolherem a vida que elas com justiça valorizam. (SEM 2000, p.82).

Já no segundo grupo, mesmo havendo uma clara diferença no que condiz à estrutura urbana e aos serviços ofertados, ou seja, são cidades ou região que apresenta bons serviços de saúde, escola para os filhos, lazer, atividades culturais (Museus, shows, teatro, cinema), restaurantes e, no caso do Cariri, aeroporto com voos regulares para Fortaleza que facilita e minimiza o impacto dos deslocamentos, ainda assim, os discursos dos docentes interlocutores são, de certo modo, equivalentes aos dos docentes do primeiro grupo. Logo, é possível concluir que não são apenas os serviços e equipamentos existentes em uma dada cidade que determinam as identificações com e no lugar. Além destes, existe o aspecto subjetivo, também já apresentado, designados pelo: o distanciamento familiar e dos grupos sociais extratrabalho, os anseios profissionais, ou simplesmente pautados pelo sentimento de degredo, ou seja, pela angústia decorrente do "simples" afastamento de sua terra natal por tempo determinado ou por toda a vida.

Primeiro, é uma sociedade que vem se modificando muito rapidamente, tornando-se cada vez mais complexa, heterogenia, diferenciada, com novas clivagens surgindo e cruzando transversalmente a estrutura de classe,

\footnotetext{
${ }^{5}$ A pesquisa foi realizada entre 2009 e início de 2013. Após este período, os cursos e faculdades da Universidade Federal do Ceará na Região do Cariri cearense (especialmente nas cidades de Crato, Juazeiro do Norte e Barbalha), passaram a compor a Universidade Federal do Cariri, criada em junho de 2013.
} 
desfazendo identidades tradicionais, criando outras tantas e gerando uma pluralidade de interesses e demandas nem sempre convergentes, quando não conflitantes e excludentes. É uma dinâmica societária feita de formas distintas de sociabilidade, algumas antigas e outras novas que seguem as rápidas transformações da vida urbana, da organização, da produção e do consumo; de diferenças nos usos da cidade, nos modos de fixação, e mobilidade no espaço urbano e acesso a bens materiais e simbólicos de uma sociedade de consumo pujante mas também extremamente estratificada e excludente; de diferentes e muitas formas de integração em um mercado que se altera em ritmo acelerado, desestabilizando posições consolidadas, desfazendo hierarquias ocupacionais tradicionais, subvertendo escalas de salários e qualificação, junto com as novas formas de estratificação e mobilidade ocupacional. (TELLES 1994, p. 227).

No tocante ao desejo de retorno, aos anseios profissionais, as categorias de pensamento se organizavam basicamente da seguinte forma:

1) Desejo de retorno devido a questões familiares, sobretudo quando entrevistamos professoras;

2) Desejo de retorno devido aos anseios profissionais - ser conhecido em seu lugar de origem, na faculdade que se formou, desenvolvimento de pesquisas e condições de publicação, norteavam as falas;

3) Ausência desse desejo por desistência ou conformação. "sempre quis, sempre fui atrás, mas nunca consegui. Hoje já me conformei e procuro esquecer dessa possibilidade" (professor Luis do curso de Direito da UVA, Sobral);

4) Desejo de permanência por identificação com o lugar e com a universidade;

5) Desejo de permanência devido organização do trabalho: "em Fortaleza, trabalharia muito mais. Lá é mais intenso e as cobranças por produtividade são maiores. Aqui trabalho dois dias e meio e me sinto confortável com essa situação". (professora Cleide, UFC de Juazeiro do Norte).

Outro destaque a ser feito é que, permanecendo ou não, as expressões eram acompanhadas, quase sempre por justificativas "coletivas", como expressadas pelo professor Neto do curso de Psicologia de Sobral e concursado desde 2008:

Se eu quero voltar, ou tenho desejo de mudar para uma outra cidade? Claro que tenho. Eu e $95 \%$ dos professores que trabalham aqui, não só sou eu. $\mathrm{O}$ pessoal diz que Sobral é uma cidade boazinha, mas só se faz algo aqui à noite. Procura um canto para ir ou algo para fazer no meio da tarde. Não tem! $\mathrm{Na}$ verdade, não dá nem para sair porque você não quer sair do $\mathrm{Ar}$ condicionado. Ou você está trabalhando - e nesse sentido é bom, pois se não tem o que fazer a cidade favorece o trabalho - ou se está dormindo. Aqui na UFC, que tem muito status, é terrível. Tivemos que mudar de prédio mais de duas vezes desde quando cheguei. Como é que você se organiza assim? 
Outra coisa, posso contar nos dedos os professores que ficam aqui... Do nosso curso só a Denise que já morava aqui, o Maciel, que é solteiro e "doidão", e eu que nem sei se moro mesmo aqui, pois na primeira oportunidade vou para Fortaleza... (Alteramos os nomes dos professores citados).

Convém deixar claro que o desejo de retorno ou a opção de ficar, não se relaciona obrigatoriamente com as competências ou compromissos destes professores com suas atividades.

Quero sim voltar para Fortaleza ou mudar para uma capital, mas enquanto estiver por aqui, vou fazer o melhor que posso, os estudantes não podem ficar à mercê dos meus anseios e, além disso, só vou mesmo conseguir sair daqui se fizer um bom trabalho, se produzir, se cumprir bem minhas atividades. Uma coisa não exclui a outra, sou professora universitária! E como tal, busco cumprir minhas atividades com excelência. (Natália, professora da URCA na cidade do Crato).

Mesmo expressando desejos de retorno ou mudança, em algumas cidades/universidades, os professores buscavam elaborar pesquisas com os recursos que dispunham naquele momento, elaboravam seminários e outras atividades acadêmicas. Nesta perspectiva, uma das expressões e sensações mais verbalizadas pelos docentes da pesquisa era: "vou fazer currículo aqui e, se Deus quiser, vou fazer concurso em outro lugar, em uma cidade maior". Mesmo professores com 10 anos (ou mais) de exercício docente na mesma IES/cidade, mantinham este desejo de retorno ou saída para outro lugar.

\section{CONSIDERAÇÕES FINAIS}

As cidades e as universidades, de forma geral, são a expressão viva de como a sociedade se relaciona entre si, e como ela busca meios de reconhecimento e convívio com os mais diferentes grupos sociais, estabelecendo relações de poder e apropriação, sobretudo na demarcação - e distinção - territorial atribuída às atividades laborais, pessoais e familiares, e na caracterização do lugar, ou seja, o recorte espacial onde as relações sociais são mais intensas.

Para Carlos (1988), o espaço urbano é o resultado do processo de trabalho da sociedade e não apenas uma concepção de localização. Na produção e reprodução do espaço urbano o indivíduo age enquanto sujeito modelador através da força de trabalho, a fim de estabelecer e manter uma cadeia relacional envolvida no processo produtivo geral da sociedade. Tudo isso, com a finalidade de se obter neste locus produzido o suprimento de suas necessidades. A mesma autora destaca ainda a 
relação dialética entre a sociedade e o espaço fazendo com que os indivíduos não só produzam, mais sim o reproduzam. Neste sentido, o trabalho humano ganha destaque, pois age enquanto mediador da relação Sociedade $x$ Espaço determinando tanto a sua natureza social, quanto às diversas formas de uso e ocupação espacial.

\begin{abstract}
O espaço não é humano porque o homem o habita, mas porque o constrói e reproduz, tornando o objeto sobre o qual recai o trabalho em algo que lhe é próprio. Por outro lado, o espaço passa a ser produzido em função do processo produtivo geral da sociedade. É assim um produto histórico que sofreu e sofre um processo de acumulação técnica cultural apresentando a cada momento as características e determinações da sociedade que a produz. (CARLOS, 1988, p. 15).
\end{abstract}

A análise da autora nos sugere que a relação cidade/universidade é possuidora de uma essência social, não podendo este ser compreendido apenas pelas rugosidades apresentadas, ou seja, não se pode compreendê-la apenas por elementos objetivos que compõem sua paisagem natural ou artificial, como seus objetos ou equipamentos urbanos que são visíveis, mas sim, entender o processo desencadeado pela ação humana sendo, portanto, produto social.

Neste sentido, notamos que a relação cidade/universidade refletida pelas percepções dos docentes interlocutores deste trabalho, constitui-se dialeticamente entre: a cidade materializada referida ao espaço social concreto, e a cidade imaterializada constituída por sua vez, de um espaço social simbólico polissêmico. Estes "dois espaços" por sua vez, são permeados por representações sociais.

Arantes em seu ensaio, A Guerra dos Lugares (1994), afirma que:

Os habitantes da cidade deslocam-se e situam-se no espaço urbano. Nesse espaço comum, cotidianamente trilhado, vão sendo construídas as fronteiras simbólicas que separam, aproximam, nivelam, hierarquizam ou, em uma palavra, ordenam as categorias e os grupos sociais em suas mútuas relações.

Desta forma, observamos que esta relação é também simbólica, cotidianamente reproduzida, onde os atores sociais se inserem, ou não, e desenvolvem atribuições liminares. Neste sentido o mesmo autor argumenta:

Como ocorre em todo espaço liminar, cruzando fronteiras entre o público e o privado, entre os gêneros, entre a necessidade e a propriedade privada, nesse ambiente as pessoas jogam com o que é familiar desfamiliarizando-o. Povoa este espaço, onde quase tudo pode acontecer... A contrapelo dessa ordem pública ritualizada, outras contratualidades e racionalidades se constituem.

Sendo assim, é possível inferir que o olhar e a percepção da relação cidade/universidade refletidos pelos professores investigados, configura-se tanto como um espaço socialmente construído, como um espaço simbólico, pois mais do 
que um território bem delimitado (territorializado), este representa uma condição subjetiva expressa pelas contradições entre o desejo de partida e o de permanência.

Nesta perspectiva, ao finalizarmos, cumpre considerar, para efeitos de análise das políticas de expansão e interiorização ocorrida no Brasil especialmente nos 15 primeiros anos do século atual, aspectos subjetivos a partir dos sujeitos que vivenciam e constroem às instituições públicas de ensino superior. Ou seja, não se trata de desconsiderar análises sobre criação de novos cursos, aumento do número de vagas e matrículas, investimentos em regiões distantes dos grandes centros urbanos, relação entre mobilidades e migrações, dentre outras. Longe disso! Em verdade, tratase de estabelecer uma importante complementação a estes estudos e, com isso, designarmos um olhar para sujeitos, estruturas e processos que, indubitavelmente, compõem importantes campos de análise nas diversas áreas das ciências sociais e humanas no que se refere à análise das políticas governamentais para educação superior. 


\title{
CITY, UNIVERSITY AND PROFESSORS' PERCEPTIONS IN THE CONTEXT OF TERTIARY EDUCATION EXPANSION IN THE COUNTRYSIDE OF CEARÁ STATE
}

\begin{abstract}
:
This paper aims to discuss the city/university relationship from the perspective of expansion process and implementation of public tertiary education institutions in the countryside of Ceará State (Brazil). This is a qualitative research that privileges narrative approaches about the professors' journeys, investigating how they perceive and establish relationships with their workplace. Interviews were carried out with Centres' directors and 49 professors (27 male and 22 female) in all the campuses in which there are public (federal or state) universities, faculties, classroom courses in Ceará State. Based on this material, it was possible to verify that there are several difficulties expressed by the professors related to their awareness and sense of belonging to their workplace the process of implementation of tertiary education in the countryside should be performed also considering the subjective aspects of the individuals that are part of these institutions; the structural difficulties of the cities and the way the professors perceive them, feel and identify themselves with these cities may interfere in the conditions and organization of their work.

Keywords: Tertiary Education. Expansion and Countryside Implementation. City And University. Teaching Work.

\section{CIUDAD, UNIVERSIDAD Y PERCEPCIONES DOCENTES EN EL CONTEXTO DE LA EXPANSIÓN DE LA ENSEÑANZA SUPERIOR PÚBLICA HACIA EL INTERIOR DEL ESTADO DE CEARÁ}

\section{Resumen:}

Este artículo tiene como objetivo discutir la relación ciudad/universidad a partir del proceso de expansión de las instituciones públicas de enseñanza de nivel superior hacia el interior del estado de Ceará, Brasil. El desarrollo de esta investigación se basa en una metodología de base cualitativa, privilegiando abordajes narrativos sobre las trayectorias docentes, investigando la manera como los mismos perciben y mantienen relaciones con el local de trabajo. Fueron realizadas entrevistas con directores de centros y con 49 docentes ( 27 de género masculino y 22 de género femenino) en todos los campus donde existen universidades, facultades, cursos presenciales del sistema público (estadual y/o federal) en Ceará. A partir del material producido fue posible constatar que existen innúmeras dificultades de reconocimiento y pertenencia del/de la docente con su local de trabajo, que el análisis de la interiorización de la enseñanza superior debe ser realizada, también, considerando aspectos subjetivos de los sujetos que las constituyen, que las dificultades estructurales de las ciudades y la manera como el/la docente percibe, siente y se identifica con estas ciudades puede resbalar sobre las condiciones y organización del trabajo por él/ella desarrollado.

Palabras-claves: Enseñanza Superior. Expansión y Interiorización. Ciudad y Universidad. Trabajo Docente. 


\section{REFERÊNCIAS}

ANDRADE, A. C. de. As cidades médias e suas inserções nos espaços regionais: $O$ contexto do sul de Minas. Revista Territorium Terram, v. 3, n. 5, p.64-79, jan/jun, 2015.

ARANTES, A..A. A guerra dos lugares: sobre fronteiras simbólicas e liminaridades no espaço urbano. Revista do Patrimônio Histórico e Artístico Nacional, IPHAN. Rio de Janeiro, v.1, n. 23, p. 190-203, 1994.

CARLOS, A. F. A. Espaço e Indústria. São Paulo: contexto/EDUSP, 1988.

. O Espaço Urbano: novos escritos sobre a cidade. São Paulo: contexto, 2004.

CHATIER, R. História cultural - entre práticas e representações. São Paulo: DIFEL, 1990.

CLAVAL, Paul. Politics and the university. In: WUSTEN, Herman van der (ed.). The urban university and its identity. Roots, locations, roles. Dordrecht: Kluwer Academic Publishers, 1998. p. 29-46.

CORREAA, R. L. As pequenas cidades na confluência do urbano e do rural. GEOUSP - Espaço e Tempo, São Paulo, № 30, p. 05 - 12, 2011.

DE CERTEAU, Michel. A invenção do cotidiano: Artes de fazer. Trad. Ephraim F. Alves. Petrópolis, 1994.

HENRIQUE, W. Dinâmicas urbanas e regionais em cidades médias após a instalação de universidades públicas. In: XII Seminário da Rede Iberoamericana de Pesquisadores sobre Globalização e Território, 2012, Belo Horizonte. Anais do XII Seminário da RII, 2012. v. 01. p. 01-16.

KOGA, D. MEDIDAS DE CIDADES: entre territórios de vida e territórios vividos. São Paulo: Cortez, 2003.

LIMA, Antonia Jesuíta de. As Multifaces da Pobreza: formas de vida e representações simbólicas dos pobres urbanos. Teresina: Halley, 2003. 
OLIVEIRA, Francisco de. A Economia Brasileira: Crítica à Razão Dualista.

Petrópolis - RJ: Vozes, 1995.

PAULA, J.A. de. A cidade e a Universidade. In: BRANDÃO, C.A.L. (org.). As cidades da cidade. Belo Horizonte, EdUFMG, 2006.

PINHEIRO, C.H.L. Desenvolvimento urbano e seus reflexos socioespaciais: Estudo da relação entre a população e uma política de produção do espaço urbano no Arraial Moura Brasil - Fortaleza - Ceará. (Dissertação). Programa de PósGraduação em Políticas Públicas e Sociedade - Universidade Estadual do Ceará, 2007.

SCHALLER, Jean-Jacques. Lugares Aprendentes e Inteligência Coletiva: rumo à construção de um mundo comum. In: PASSEGGI, M. C. ; SOUZA, E. C. de (org.). (auto)biografia: formação, territórios e saberes. Natal, RN; São Paulo, Paulus, 2008.

SANTOS, M. Da totalidade ao lugar. São Paulo: EdUSP, 2012.

Espaço e método. São Paulo: Nobel, 1997a.

SEM. Amartya Kumar. Desenvolvimento com liberdade. São Paulo, Companhia das Letras, 2000.

TELLES, Vera de S. Pobreza, movimentos sociais e cultura política: notas sobre as difíceis relações entre pobreza, direito e democracia. In: DINIZ, Eli (Org.). O Brasil no rastro da crise. São Paulo, HUCITEC, 1994. 